\title{
Identification of Two Sulfated Cholesterol Metabolites Found in the Urine of a Patient with Niemann-Pick Disease Type C as Novel Candidate Diagnostic Markers
}

\author{
Masamitsu Maekawa ${ }^{1}$, Kaoru Omura ${ }^{2}$, Shoutaro Sekiguchi², Takashi Iida ${ }^{2}$, \\ Daisuke Saigusa ${ }^{1,3}$, Hiroaki Yamaguchi ${ }^{1}$, and Nariyasu Mano ${ }^{* 1}$ \\ ${ }^{1}$ Department of Pharmaceutical Sciences, Tohoku University Hospital, 1-1 Seiryo-machi, Aoba-ku, Sendai 980-8574, Japan \\ ${ }^{2}$ College of Humanities and Sciences, Nihon University, 3-25-40 Sakurajousui, Setagaya-ku, Tokyo 156-8550, Japan \\ ${ }^{3}$ Department of Integrative Genomics, Tohoku Medical Megabank Organization, Tohoku University, \\ 2-1 Seiryo-machi, Aoba-ku, Sendai 980-8575, Japan
}

In the urine of a Niemann-Pick disease type C (NPC) patient, we have identified three characteristic intense peaks that have not been observed in the urine of a $3 \beta$-hydroxysteroid- $\Delta^{5}-\mathrm{C}_{27}$-steroid dehydrogenase deficiency patient or a healthy infant and adult. Based on accurate masses of the protonated molecules, we focused on two of them as candidate NPC diagnostic markers. Two synthesized authentic preparations agreed with the two compounds found in NPC patient urine in regard to both chromatographic behavior and accurate masses of the deprotonated molecules. Moreover, the isotopic patterns of the deprotonated molecules, twin peaks unique to the sulfur-containing compounds appearing in their second isotope positions, and accurate masses of product ions observed at $\mathrm{m} / \mathrm{z} 97$ also agreed between the target compounds and authentic preparations. We identified the two compounds as the sulfated cholesterol metabolites as $3 \beta$-sulfooxy-7 $\beta$-hydroxy-5-cholen-24-oic acid and $3 \beta$-sulfooxy-7-oxo-5-cholen-24-oic acid. These two compounds represent more promising candidate diagnostic markers for NPC diagnosis than three other candidates that are multiple conjugates of cholesterol metabolites, $3 \beta$-sulfooxy- $7 \beta$ - $N$-acetylglucosaminyl-5cholen-24-oic acid and its glycine and taurine conjugates, although we have reported an analytical method for determining the urinary levels of these compounds using liquid chromatography/electrospray ionization tandem mass spectrometry, because of their lack of $N$-acetylglucosamine conjugation.

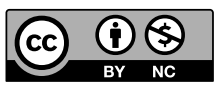

Copyright ( $) 2016$ Masamitsu Maekawa, Kaoru Omura, Shoutaro Sekiguchi, Takashi Iida, Daisuke Saigusa, Hiroaki Yamaguchi, and Nariyasu Mano. This is an open access article distributed under the terms of Creative Commons Attribution License, which permits use, distribution, and reproduction in any medium, provided the original work is properly cited and is not used for commercial purposes.

Please cite this article as: Mass Spectrom (Tokyo) 2016; 5(2): S0053

Keywords: Niemann-Pick disease type C, diagnostic markers, sulfated cholesterol metabolites, metabolite identification, high-resolution mass spectrometry

(Received September 8, 2016; Accepted October 17, 2016)

\section{INTRODUCTION}

Niemann-Pick disease type C (NPC), an autosomal recessive genetic disorder, ${ }^{1)}$ is difficult to diagnose due to its complex symptoms, which depend on age of onset. ${ }^{2}$ Recently, we developed an analytical method for focused metabolomics using liquid chromatography/electrospray ionization tandem mass spectrometry (LC/ESI-MS/MS), and analyzed sulfated cholesterol metabolites in the urine of an NPC patient to identify diagnostic marker candidates. ${ }^{3)}$ We detected abnormal multi-conjugated cholesterol metabolites, $\quad 3 \beta$-sulfooxy-7 $\beta$ - $N$-acetylglucosaminyl-5-cholen-24oic acid (SNAG- $\Delta^{5}-\mathrm{CA}$ ) and its glycine (SNAG- $\left.\Delta^{5}-\mathrm{CG}\right)$ and taurine conjugates (SNAG- $\Delta^{5}-\mathrm{CT}$ ), which were reported in the urine of an NPC patient by Alvelius and co-workers, ${ }^{4)}$ as well as three other metabolites. ${ }^{3)}$ The latter three compounds were different from metabolites found in the urine from a patient of $3 \beta$-hydroxysteroid- $\Delta^{5}-\mathrm{C}_{27}$-steroid dehydrogenase (3 $\beta$-HSD) deficiency, a healthy adult, or a normal infant.

\footnotetext{
*Correspondence to: Nariyasu Mano, Department of Pharmaceutical Sciences, Tohoku University Hospital, 1-1 Seiryo-machi, Aoba-ku, Sendai 980-8574, Japan, e-mail: mano@hosp.tohoku.ac.jp

Abbreviations: AGC, automatic gain control; ESI, electrospray ionization; EtOAc, ethyl acetate; HPLC, high-performance liquid chromatography; HRMS, highresolution mass spectrometry; IT, injection time; $3 \beta$-HSD, $3 \beta$-hydroxysteroid- $\Delta^{5}-\mathrm{C}_{27}$-steroid dehydrogenase; LC/ESI-MS/MS, liquid chromatography/electrospray ionization tandem mass spectrometry; LC/MS, liquid chromatography/mass spectrometry; NCE, normalized collision energy; NPC, Niemann-Pick disease type C; SNAG- $\Delta^{5}$-CA, $3 \beta$-sulfooxy-7 $\beta$ - $N$-acetylglucosaminyl-5-cholen-24-oic acid; SNAG- $\Delta^{5}$-CG, $3 \beta$-sulfooxy-7 $\beta$ - $N$-acetylglucosaminyl-5-cholen-24-oic acid glycine conjugate; SNAG- $\Delta^{5}$-CT, $3 \beta$-sulfooxy-7 $\beta$ - $N$-acetylglucosaminyl-5-cholen-24-oic acid taurine conjugate; TBDMS, tert-butyldimethylsilyl; RF, radio frequency; UDP, uridine $5^{\prime}$-diphosphate; UGT, UDP glycosyltransferase
} 
We believe these molecules present new candidates for NPC diagnostic markers, and therefore sought to identify them.

In this study, we first estimated the compounds' structures from their masses, retention times, and possible biosynthesis routes. Next, we synthesized potential metabolites, subjected them to LC/ESI-MS/MS on a high-resolution instrument, and compared the results with the target metabolites.

\section{EXPERIMENTAL METHODS}

\section{Materials}

Ultrapure water was prepared using a PURELAB ultra apparatus (Organo, Tokyo, Japan). Methanol, ammonium acetate, and ammonia solution were purchased from Wako Pure Chemical Industries, Ltd. (Osaka, Japan). All other chemicals were analytical grade and solvents were HPLC or LC/MS grade. $3 \beta$-Sulfooxy-7 $\beta$-hydroxy-5-cholen-24-oic acid disodium salt was synthesized according to the synthetic scheme shown in later. $3 \beta$-Sulfooxy-7-oxo-5-cholen-24-oic acid disodium salt was an authentic standard that we had synthesized previously. ${ }^{5}$ ) The urine of a 3-month-old male NPC patient was kindly supplied by Tottori University Hospital (Tottori, Japan) and frozen at $-80^{\circ} \mathrm{C}$ until use. This study was carried out according to a protocol approved by the ethical committee of the Graduate School of Medicine in Tohoku University.

\section{LC/ESI-MS/MS analysis of the urine of an NPC patient}

One-hundred microliters of NPC patient urine was diluted with $900 \mu \mathrm{L}$ of water, $100 \mu \mathrm{L}$ of the diluted urine was then mixed with $100 \mu \mathrm{L}$ of water. After mixing and centrifugation $\left(14,000 \times g, 5 \mathrm{~min}, 4^{\circ} \mathrm{C}\right), 50 \mu \mathrm{L}$ of supernatant was injected into the LC/ESI-MS/MS system.

LC conditions were as the previously described. ${ }^{3)}$ A Nanospace SI-2 LC system (Shiseido, Tokyo) was used. Online solid-phase extraction was achieved on a Shim-pack MAYIC8 trapping column $(50 \mu \mathrm{m}, 4.6 \mathrm{~mm}$ i.d. $\times 10 \mathrm{~mm}$, Shimadzu, Kyoto, Japan) with a mixture of $20 \mathrm{mmol} / \mathrm{L}$ ammonium acetate solution $(\mathrm{pH} 7.0) /$ methanol $(9: 1, \mathrm{v} / \mathrm{v})$ at a flow rate of $1.0 \mathrm{~mL} / \mathrm{min}$ for $3 \mathrm{~min}$. Chromatographic separation was achieved on a YMC-Pack Pro C18 column $(5 \mu \mathrm{m}, 2.0 \mathrm{~mm}$ i.d. $\times 250 \mathrm{~mm}, \mathrm{YMC}$, Kyoto) with binary gradient elution using a mixture of $20 \mathrm{mmol} / \mathrm{L}$ ammonium acetate solution $(\mathrm{pH}$ $7.0) /$ methanol $(19: 1, \mathrm{v} / \mathrm{v})$ as mobile phase A and a mixture of $20 \mathrm{mmol} / \mathrm{L}$ ammonium acetate solution $(\mathrm{pH} 7.0) /$ methanol $(1: 19, \mathrm{v} / \mathrm{v})$ as mobile phase B. Equilibration was performed with $50 \%$ of mobile phase B. Percentage of mobile phase B (B\%) was shifted to $80 \%$ linearly over $120 \mathrm{~min}$.

High-resolution and accurate tandem mass spectrometry was performed on a Q Exactive hybrid quadrupole-orbitrap mass spectrometer (Thermo Fisher Scientific, Waltham, MA, USA) coupled with a heated-ESI probe. Heater and capillary temperatures were set at 450 and $320^{\circ} \mathrm{C}$, respectively, and spray voltage was set at $-3.5 \mathrm{kV}$. Flow rate of sheath gas, aux gas, and sweep gas were set at 50,20, and 1 units, respectively. S-lens RF voltage was set at $50 \mathrm{~V}$. Data from two mass spectrometric analyses were acquired within each cycle. In the first analysis, MS scan ranging from $\mathrm{m} / z 100$ to 900 was performed. Mass resolution was set at 70,000 . Automatic gain control (AGC) target and maximum injection time (IT) were set at $2 \times 10^{5}$ and $0.1 \mathrm{~s}$, respectively. In the next analysis, product ion scan analysis was performed at the same resolution, AGC target, and maximum IT parameters as for the MS scan. Stepped normalized collision energy (NCE) was set at 35\%. The ions at $m / z 469.22655$ and 467.21090 were selected as precursor ions.

\section{Synthesis of $3 \beta$-sulfooxy-7 $\beta$-hydroxy-5-cholen-24- oic acid disodium salt}

\section{Methyl $3 \beta$-tert-butyldimethylsilyloxy- $\beta \beta$-acetoxy- 5-cholen-24-oate}

To a magnetically stirred solution of methyl $3 \beta$-tertbutyldimethylsilyloxy-7 $\beta$-hydroxy-5-cholen-24-oate $(0.61 \mathrm{~g}$, $1.2 \mathrm{mmol}$ ) in pyridine $(10 \mathrm{~mL})$, prepared in eight steps from chenodeoxycholic acid ( $3 \alpha, 7 \alpha$-dihydroxy- $5 \beta$-cholan-24-oic acid), ${ }^{5,6)}$ was added 4,4 -dimethylaminopyridine $(60 \mathrm{mg})$ in acetic anhydride $(5 \mathrm{~mL})$. After stirring at $50^{\circ} \mathrm{C}$ for $2 \mathrm{~h}$, the reaction product was extracted with EtOAc. The combined extract was washed with $10 \% \mathrm{HCl}$, saturated $\mathrm{NaHCO}_{3}$, and saturated brine, dried over Drierite; and evaporated under reduced pressure. Recrystallization of the residue from methanol gave the title compound as colorless needles: yield, $0.66 \mathrm{~g}$ (ca. 100\%). mp, 153-154 ${ }^{\circ} \mathrm{C} .{ }^{1} \mathrm{H}-\mathrm{NMR}\left(\mathrm{CDCl}_{3}\right)$, $\delta: 0.04\left[6 \mathrm{H}, \mathrm{s},-\mathrm{Si}\left(\mathrm{CH}_{3}\right)_{2} \mathrm{C}\left(\mathrm{CH}_{3}\right)_{3}\right], 0.68\left(3 \mathrm{H}, \mathrm{s}, 18-\mathrm{CH}_{3}\right), 0.87$ $\left[9 \mathrm{H}, \mathrm{s},-\mathrm{Si}\left(\mathrm{CH}_{3}\right)_{2} \mathrm{C}\left(\underline{\mathrm{CH}}_{3}\right)_{3}\right], 0.91\left(3 \mathrm{H}, \mathrm{d}, J=6.8 \mathrm{~Hz}, 21-\mathrm{CH}_{3}\right)$, $1.05\left(3 \mathrm{H}, \mathrm{s}, 19-\mathrm{CH}_{3}\right), 2.01\left(3 \mathrm{H}, \mathrm{s},-\mathrm{OCOCH}_{3}\right), 3.48(1 \mathrm{H}, \mathrm{br} \mathrm{m}$, $3 \alpha-\mathrm{H}), 3.65\left(3 \mathrm{H}, \mathrm{s},-\mathrm{COOCH}_{3}\right), 5.00(1 \mathrm{H}, \mathrm{dm}, J=8.6 \mathrm{~Hz}$, $7 \alpha-\mathrm{H}), 5.18(1 \mathrm{H}, \mathrm{s}, 6-\mathrm{H}) .{ }^{13} \mathrm{C}-\mathrm{NMR}\left(\mathrm{CDCl}_{3}\right), \delta:-4.65,11.75$, $18.23,18.32,19.05,21.02,21.67,25.13,25.89,28.23,30.94$, $31.03,31.93,35.26,36.46,36.93,39.34,42.21,42.85,48.16$, $51.51,55.04,55.52,72.03,75.82,120.87,145.94,171.34$, 174.70. ESI-HRMS, calculated for $\mathrm{C}_{33} \mathrm{H}_{56} \mathrm{O}_{5} \mathrm{NaSi}[\mathrm{M}+\mathrm{Na}]^{+}$: 583.3750; found, $m / z: 583.3749$.

\section{Methyl $3 \beta$-hydroxy-7 $\beta$-acetoxy-5-cholen-24-oate}

A solution of methyl $3 \beta$-tert-butyldimethylsilyloxy- $7 \beta$ acetoxy-5-cholen-24-oate $(652 \mathrm{mg}, 1.2 \mathrm{mmol})$ dissolved in acetone $(5 \mathrm{~mL})$ and methanol $(5 \mathrm{~mL})$ mixture containing $10 \% \mathrm{HCl}(1 \mathrm{~mL})$ was stirred at room temperature for $10 \mathrm{~min}$. After evaporation of the solvents under reduced pressure, the residual oily product was extracted with EtOAc. The combined EtOAc extract was washed with saturated brine, dried over Drierite, and evaporated to dryness. Recrystallization of the residue from $\mathrm{CH}_{2} \mathrm{Cl}_{2}$-hexane gave the desired compound as a colorless amorphous solid: yield, $444 \mathrm{mg}$ (86\%). mp, $144-145^{\circ} \mathrm{C} .{ }^{1} \mathrm{H}-\mathrm{NMR}\left(\mathrm{CDCl}_{3}\right), \delta: 0.70$ $\left(3 \mathrm{H}, \mathrm{s}, 18-\mathrm{CH}_{3}\right), 0.92\left(3 \mathrm{H}, \mathrm{d}, J=6.8 \mathrm{~Hz}, 21-\mathrm{CH}_{3}\right), 1.07(3 \mathrm{H}$, s, $\left.19-\mathrm{CH}_{3}\right), 2.03\left(3 \mathrm{H}, \mathrm{s},-\mathrm{OCOCH}_{3}\right), 3.56(1 \mathrm{H}$, br m, $3 \alpha-\mathrm{H})$, $3.66\left(3 \mathrm{H}, \mathrm{s},-\mathrm{COOCH}_{3}\right), 5.03(1 \mathrm{H}, \mathrm{dm}, J=8.1 \mathrm{~Hz}, 7 \alpha-\mathrm{H}), 5.21$ $(1 \mathrm{H}, \mathrm{s}, 6-\mathrm{H}) .{ }^{13} \mathrm{C}-\mathrm{NMR}\left(\mathrm{CDCl}_{3}\right), \delta: 11.68,18.23,18.95,20.95$, $21.58,25.01,28.13,30.84,30.93,31.25,35.16,36.30,36.72$, $39.22,41.51,42.76,48.01,51.43,54.94,55.38,70.93,75.62$, 121.13, 145.26, 171.25, 174.64. ESI-HRMS, calculated for $\mathrm{C}_{27} \mathrm{H}_{42} \mathrm{O}_{5} \mathrm{Na}[\mathrm{M}+\mathrm{Na}]^{+}$: 469.2930; found, $m / z: 469.2922$.

\section{$3 \beta$-Sulfooxy-7 $\beta$-hydroxy-5-cholen-24-oic acid di- sodium salt}

To a magnetically stirred solution of methyl $3 \beta$-hydroxy$7 \beta$-acetoxy-5-cholen- 24 -oate $(444 \mathrm{mg}, 1.0 \mathrm{mmol}$ ) in pyridine $(5 \mathrm{~mL})$ was added sulfur trioxide-trimethylamine complex (750 mg), and the mixture was stirred at room temperature 
for $1 \mathrm{~h}$. After decantation of the reaction mixture with petroleum ether for several times to remove insoluble materials and then evaporation of the solvent, the residue dissolved in $10 \% \mathrm{NaOH}$ solution $(10 \mathrm{~mL})$ was refluxed overnight. The resultant solution was adjusted to $\mathrm{pH} 8$ with $10 \% \mathrm{HCl}$ and passed through a reversed-phase Sep-Pak Vac $\mathrm{tC}_{18}$ cartridge $(10 \mathrm{~g})$. Elution with methanol/water $(1: 1, \mathrm{v} / \mathrm{v})$ afforded the desired compound, which was recrystallized from methanol/EtOAc as a colorless amorphous solid: yield, $384 \mathrm{mg}$ (75\%). Discolored to dark brown at ca. $215^{\circ} \mathrm{C}$ (decomposition). ${ }^{1} \mathrm{H}-\mathrm{NMR}\left(\mathrm{CD}_{3} \mathrm{OD}\right), \delta: 0.71\left(3 \mathrm{H}, \mathrm{s}, 18-\mathrm{CH}_{3}\right)$, $0.95\left(3 \mathrm{H}, \mathrm{d}, J=6.8 \mathrm{~Hz}, 21-\mathrm{CH}_{3}\right), 1.06\left(3 \mathrm{H}, \mathrm{s}, 19-\mathrm{CH}_{3}\right), 3.72$ $(1 \mathrm{H}, \mathrm{dm}, J=8.0 \mathrm{~Hz}, 7 \alpha-\mathrm{H}), 4.14(1 \mathrm{H}$, br m, $3 \alpha-\mathrm{H}), 5.28(1 \mathrm{H}$, s, 6-H). ${ }^{13} \mathrm{C}-\mathrm{NMR}\left(\mathrm{CD}_{3} \mathrm{OD}\right), \delta$ : 12.34, 19.07, 19.34, 22.21, $27.35,29.51,29.95,34.07,36.23,37.24,37.51,38.10,39.90$, 40.98, 41.11, 44.04, 48.05, 56.92, 57.68, 73.69, 79.41, 128.23, 143.34, 183.68. ESI-HR-MS, calculated for $\mathrm{C}_{24} \mathrm{H}_{37} \mathrm{O}_{7} \mathrm{~S}$ $[\mathrm{M}-2 \mathrm{Na}+2 \mathrm{H}-\mathrm{H}]^{-}:$469.2260; found, $m / z: 469.2245$.

\section{LC/ESI-HRMS and LC/ESI-HRMS/MS analysis of authentic standards}

Both authentic standards, $3 \beta$-sulfooxy-7 $\beta$-hydroxy-5cholen-24-oic acid disodium salt and $3 \beta$-sulfooxy-7-oxo-5cholen-24-oic acid disodium salt, were dissolved and diluted at $1.0 \mu \mathrm{g} / \mathrm{mL}$ concentration with water/ethanol $(1: 1, \mathrm{v} / \mathrm{v})$. One hundred microliters of diluted urine or standard solutions was mixed with $100 \mu \mathrm{L}$ of water. After centrifugation $\left(14,000 \times g, 5 \mathrm{~min}, 4^{\circ} \mathrm{C}\right), 50 \mu \mathrm{L}$ of supernatant was subjected to LC/ESI-MS/MS analysis. LC/ESI-MS/MS was performed under the above-mentioned conditions except for resolution, which was set at 140,000.

\section{RESULTS AND DISCUSSION}

Three peaks at $m / z 453,467$, and 469 , detected in the urine of an NPC patient in a previous report, were determined to be singly charged ions possessing a sulfate group, as indicated by the generation of $\mathrm{HSO}_{4}^{-}$as a product ion. ${ }^{3)}$ In the earlier report, we estimated their compositions as $\mathrm{C}_{24} \mathrm{H}_{38} \mathrm{O}_{6} \mathrm{~S}, \mathrm{C}_{24} \mathrm{H}_{36} \mathrm{O}_{7} \mathrm{~S}$, and $\mathrm{C}_{24} \mathrm{H}_{38} \mathrm{O}_{7} \mathrm{~S}$, respectively. ${ }^{3)}$ In this study, we analyzed the three compounds on a Q-Exactive hybrid quadrupole-orbitrap mass spectrometer, which can analyze mass at high accuracy (within $5 \mathrm{ppm}$ ). Results are shown in Table 1. Although the accurately measured masses of two peaks, $m / z 467$ and 469 (estimated as $\mathrm{C}_{24} \mathrm{H}_{36} \mathrm{O}_{7} \mathrm{~S}$ and $\mathrm{C}_{24} \mathrm{H}_{38} \mathrm{O}_{7} \mathrm{~S}$, respectively), were in close agreement with their theoretical values $(\Delta \mathrm{mmu}$, approximately 0.7$)$, the peak at $m / z 453$ disagreed with the theoretical value for $\mathrm{C}_{24} \mathrm{H}_{38} \mathrm{O}_{6} \mathrm{~S}$. Four candidate compounds were within the range of $5 \mathrm{ppm}$ of these values, but $\mathrm{C}_{25} \mathrm{H}_{27} \mathrm{O}_{5} \mathrm{NS}$ was excluded as a probable composition because of the nitrogen rule. We could also eliminate $\mathrm{C}_{22} \mathrm{H}_{29} \mathrm{O}_{8} \mathrm{~S}$ and $\mathrm{C}_{14} \mathrm{H}_{33} \mathrm{O}_{10} \mathrm{~N}_{2} \mathrm{~S}_{2}$ because these compounds are not natural steroids. The degree of unsaturation of $\mathrm{C}_{19} \mathrm{H}_{33} \mathrm{O}_{8} \mathrm{~S}_{2}$ is six, and it cannot contain any double bonds in its structure if it is a steroid sulfate. Because no such compound occurs naturally, we eliminated the peak at $\mathrm{m} / z 453$ as a candidate diagnostic biomarker for NPC.

Another compound with the same composition formula as $\mathrm{C}_{24} \mathrm{H}_{38} \mathrm{O}_{7} \mathrm{~S}$ was detected in the urine of a patient with $3 \beta$-HSD deficiency in our previous report ${ }^{3)}$; however, its retention time $\left(t_{\mathrm{R}}, 33.5 \mathrm{~min}\right)$ was significantly different from that of the target compound at $m / z 469\left(t_{\mathrm{R}}, 21.0 \mathrm{~min}\right)$. $3 \beta, 7 \alpha$-Dihydroxy-5-cholen-24-oic acid and its conjugates are present in blood and urine of $3 \beta$-HSD deficiency patients, ${ }^{7,8)}$ and the peak with a retention time of $33.5 \mathrm{~min}$ has been identified as $3 \beta$-sulfooxy-7 $\alpha$-hydroxy-5-cholen-24-oic acid based on comparison of retention times with those of authentic preparations. The retention time of the peak at $m / z 469$ found in the urine of the NPC patient was substantially shorter than that of $3 \beta$-sulfooxy-7 $\alpha$-hydroxy-5cholen-24-oic acid. ${ }^{3)}$ The retention times of bile acid analogs are greatly affected by the direction of hydroxy groups on the steroid skeleton. ${ }^{9,10)}$ For example, ursodeoxycholic acid ( $3 \alpha, 7 \beta$-dihydroxy- $5 \beta$-cholanoic acid) which has a hydroxy group at the $\mathrm{C}-7 \beta$ position, is eluted more rapidly than its isomer chenodeoxycholic acid $(3 \alpha, 7 \alpha$-dihydroxy- $5 \beta$ cholanoic acid), in reversed-phase HPLC. ${ }^{9,10)}$ In addition, 5 -cholenoic acid has a wider $\beta$-side of the steroid skeleton than $5 \beta$-cholanoic acid, indicating that its retention time is more likely to be affected by the positions of hydroxy groups on the steroid skeleton. ${ }^{11)}$ Therefore, we speculated the compound observed at $\mathrm{m} / z 469$ included a hydroxy group at the C-7 $\beta$ position.

Three multi-conjugated cholesterol metabolites, SNAG$\Delta^{5}$-CA, SNAG- $\Delta^{5}-\mathrm{CG}$, and SNAG- $\Delta^{5}-\mathrm{CT}$, which were detected in the urine of an NPC patient by Alvelius and co-workers, ${ }^{4)}$ are strong candidates for NPC diagnostic markers. ${ }^{12)}$ These compounds are conjugates of sulfuric acid, $N$-acetylglucosamine, and amino acids at the C-3, C-7, and $\mathrm{C}-24$ positions, respectively, of $3 \beta, 7 \beta$-dihydroxy-5-cholen24-oic acid (molecular weight $=390$; composition $=\mathrm{C}_{24} \mathrm{H}_{38} \mathrm{O}_{4}$ ). The composition formula of the peak at $\mathrm{m} / z 469$ as a deprotonated molecule is probably $\mathrm{C}_{24} \mathrm{H}_{38} \mathrm{O}_{7} \mathrm{~S}$ as mentioned above, and the difference between $\mathrm{C}_{24} \mathrm{H}_{38} \mathrm{O}_{4}$ and $\mathrm{C}_{24} \mathrm{H}_{38} \mathrm{O}_{7} \mathrm{~S}$

Table 1. Accurate mass and candidate formulas of three peaks in the urine of the NPC patient.

\begin{tabular}{|c|c|c|c|c|c|c|}
\hline No. & $\begin{array}{l}\text { Retention time } \\
(\mathrm{min})\end{array}$ & $\begin{array}{l}\text { Observed mass } \\
\qquad(\mathrm{m} / z)\end{array}$ & Candidate formula & $\begin{array}{l}\text { Theoretical mass } \\
\qquad(\mathrm{m} / z)\end{array}$ & $\begin{array}{l}\text { Difference from } \\
\text { observed mass } \\
(\Delta \mathrm{mmu})\end{array}$ & $\begin{array}{c}\text { Difference from } \\
\text { theoretical mass (ppm) }\end{array}$ \\
\hline \multirow[t]{4}{*}{1} & 13.4 & 453.1590 & $\mathrm{C}_{25} \mathrm{H}_{28} \mathrm{O}_{5} \mathrm{NS}$ & 453.1605 & 1.45 & 3.200 \\
\hline & & & $\mathrm{C}_{22} \mathrm{H}_{30} \mathrm{O}_{8} \mathrm{~S}$ & 453.1578 & -1.24 & -2.736 \\
\hline & & & $\mathrm{C}_{19} \mathrm{H}_{34} \mathrm{O}_{8} \mathrm{~S}_{2}$ & 453.1611 & 2.14 & 4.722 \\
\hline & & & $\mathrm{C}_{14} \mathrm{H}_{33} \mathrm{O}_{10} \mathrm{~N}_{2} \mathrm{~S}_{2}$ & 453.1571 & -1.89 & -4.171 \\
\hline \multirow[t]{3}{*}{2} & 17.5 & 469.2268 & $\mathrm{C}_{24} \mathrm{H}_{38} \mathrm{O}_{7} \mathrm{~S}$ & 469.2260 & -0.78 & -1.662 \\
\hline & & & $\mathrm{C}_{27} \mathrm{H}_{35} \mathrm{O}_{4} \mathrm{NS}$ & 469.2281 & 1.35 & 2.877 \\
\hline & & & $\mathrm{C}_{21} \mathrm{H}_{42} \mathrm{O}_{7} \mathrm{~S}_{2}$ & 469.2288 & 2.04 & 4.348 \\
\hline \multirow[t]{3}{*}{3} & 19.6 & 467.2111 & $\mathrm{C}_{24} \mathrm{H}_{36} \mathrm{O}_{7} \mathrm{~S}^{2}$ & 469.2104 & -0.70 & -1.492 \\
\hline & & & $\mathrm{C}_{27} \mathrm{H}_{33} \mathrm{O}_{4} \mathrm{NS}$ & 469.2125 & 1.38 & 2.941 \\
\hline & & & $\mathrm{C}_{21} \mathrm{H}_{40} \mathrm{O}_{7} \mathrm{~S}_{2}$ & 469.2132 & 2.07 & 4.412 \\
\hline
\end{tabular}


is $\mathrm{SO}_{3}$, suggesting that $\mathrm{C}_{24} \mathrm{H}_{38} \mathrm{O}_{7} \mathrm{~S}$ may be a sulfate conjugate of $3 \beta, 7 \beta$-dihydroxy-5-cholen-24-oic acid, as shown in Fig. $1 \mathrm{~A}$. In a similar manner, we speculated that the compound observed at $\mathrm{m} / \mathrm{z} 467$ as a deprotonated molecule was a sulfate conjugate of $3 \beta$-hydroxy-7-oxo-5-cholen-24-oic acid $\left(\mathrm{C}_{24} \mathrm{H}_{36} \mathrm{O}_{7} \mathrm{~S}\right)$ (Fig. 1B). Therefore, we prepared these two authentic compounds.

We previously synthesized methyl $3 \beta$-tert-butyldimethylsilyloxy-7 $\beta$-hydroxy-5-cholen-24-oate (2) in eight steps from chenodeoxycholic acid ${ }^{5,6)}$; its precursor substance is methyl
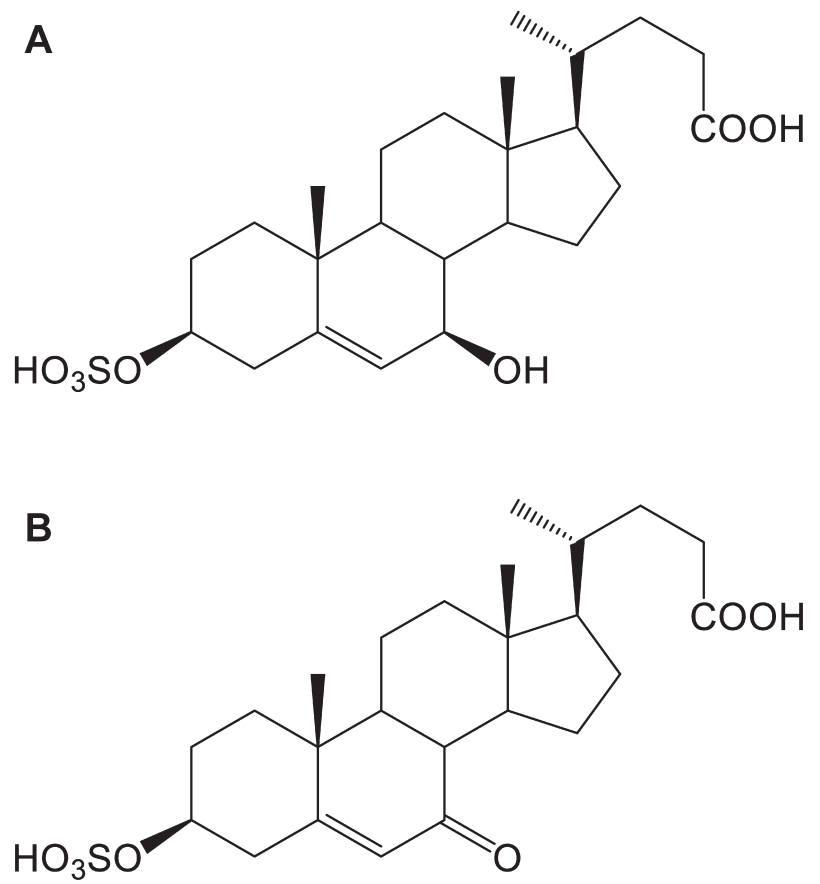

Fig. 1. Proposed structures of the candidate diagnostic markers for NPC found at $m / z 469$ (A) and 467 (B).
$3 \beta$-tert-butyldimethylsilyloxy-7-oxo-5-cholen-24-oate (1), as shown in Fig. 2. After acetylation of the hydroxy group at the C-7 position of compound 2, deprotection of a TBDMS group was performed to yield compound 4 . That product was sulfated to a hydroxy group at the C-3 position, and then hydrolyzed to prepare $3 \beta$-sulfooxy-7 $\beta$-hydroxy-5cholen-24-oic acid (5). Compound 1, oxo-form, was converted to $3 \beta$-sulfooxy-7-oxo-5-cholen-24-oic acid (7) in a similar manner at reasonable isolated yields.

Next, we analyzed two authentic preparations, $3 \beta$-sulfooxy-7 $\beta$-hydroxy-5-cholen-24-oic acid and $3 \beta$-sulfooxy-7oxo-5-cholen-24-oic acid, and target compounds observed at $m / z 469$ and 467 found in the urine of the NPC patient ${ }^{3)}$ using an accurate high-resolution mass spectrometer coupled with an HPLC system. First, we compared retention times, and the results are shown in Fig. 3 and Table 2A. The retention times of the two compounds found in the urine of the NPC patient agreed rather well with those of the authentic preparations, $3 \beta$-sulfooxy-7 $\beta$-hydroxy-5-cholen-24-oic acid $\left(\Delta t_{\mathrm{R}}, 0.06 \mathrm{~min}\right)$ and $3 \beta$-sulfooxy-7-oxo-5-cholen-24-oic acid $\left(\Delta t_{\mathrm{R}}, 0.04 \mathrm{~min}\right)$. For purposes of metabolite identification, Summer et al. $^{13)}$ recommended comparison of orthogonal parameters such as retention time, mass spectrum, tandem mass, and isotopic pattern between metabolites and authentic standards. In addition, single peaks were detected in authentic standards spiked urine sample (Figs. 3C and $3 \mathrm{~F})$.

The mass spectra of the two target compounds and two authentic standards are shown in Fig. 4. Both target compounds, which were speculated to be $3 \beta$-sulfooxy- $7 \beta$ hydroxy-5-cholen-24-oic acid and $3 \beta$-sulfooxy-7-oxo-5cholen-24-oic acid, exhibited almost the same retention times and accurate masses as the corresponding authentic standards (Table 2B). In addition, we also compared the isotopic patterns of deprotonated molecules. The theoretical isotopic pattern of $\mathrm{C}_{24} \mathrm{H}_{38} \mathrm{O}_{7} \mathrm{~S}$ observed at $\mathrm{m} / \mathrm{z} 469$ is in-

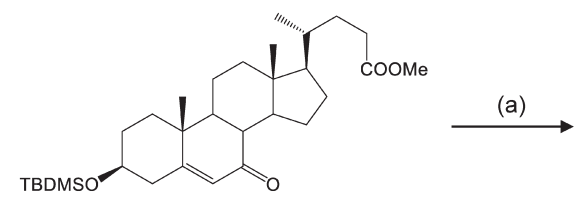

(1)

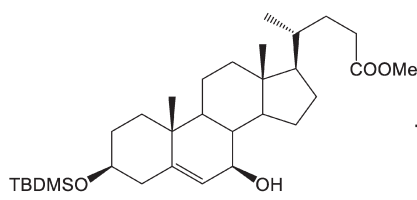

(2)

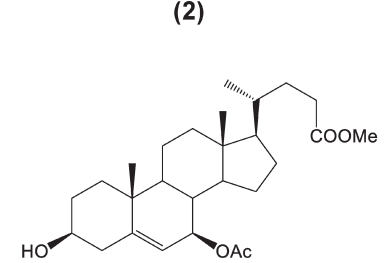

(4)

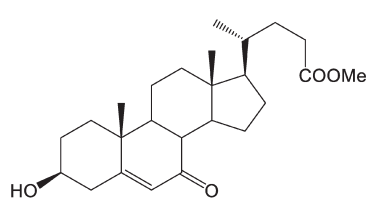

(6)

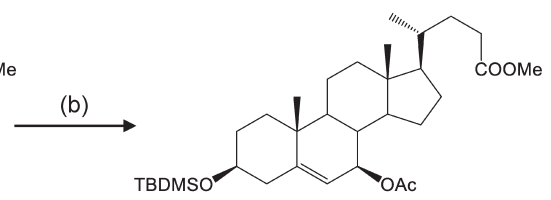

(3)
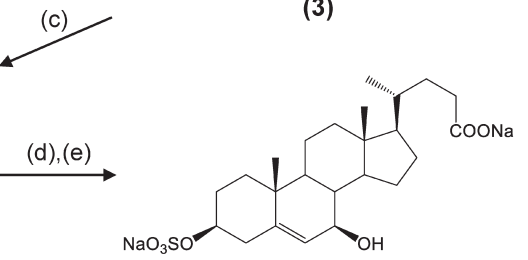

(5)

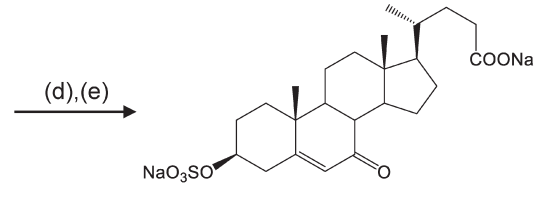

(7)

Fig. 2. Synthetic routes for authentic preparations of two candidate diagnostic markers for NPC.

Reagents and conditions: (a) zinc borohydride/dry-benzene $/ \mathrm{N}_{2}$, r.t., $2 \mathrm{~h}$; (b) acetic anhydride/pyridine $/ 4,4$-dimethylaminopyridine, $50^{\circ} \mathrm{C}$, $2 \mathrm{~h}$; (c) $10 \% \mathrm{HCl} /$ acetone $/ \mathrm{MeOH}$, r.t., $10 \mathrm{~min}$; (d) sulfur trioxide trimethylamine complex/pyridine, r.t., $1 \mathrm{~h}$; (e) $10 \% \mathrm{NaOH} / \mathrm{H}_{2} \mathrm{O}$, reflux, overnight. 
A

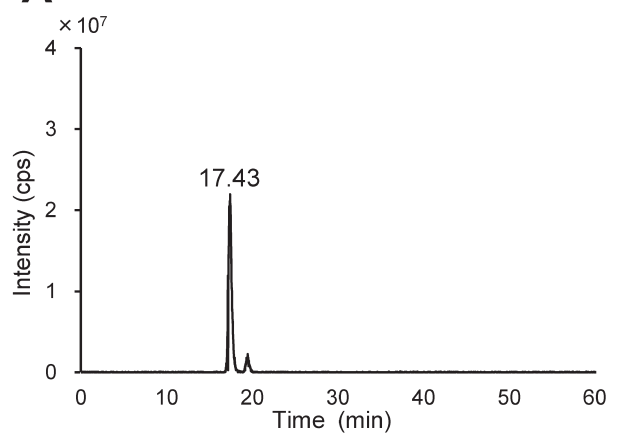

B

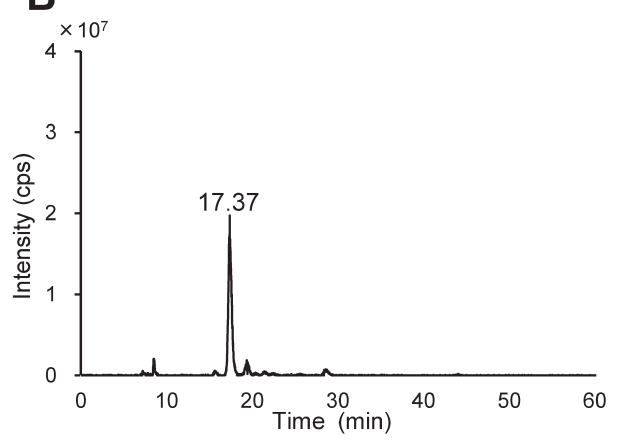

C

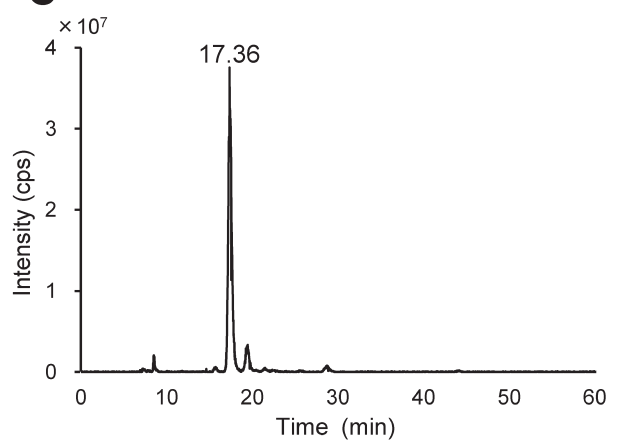

D

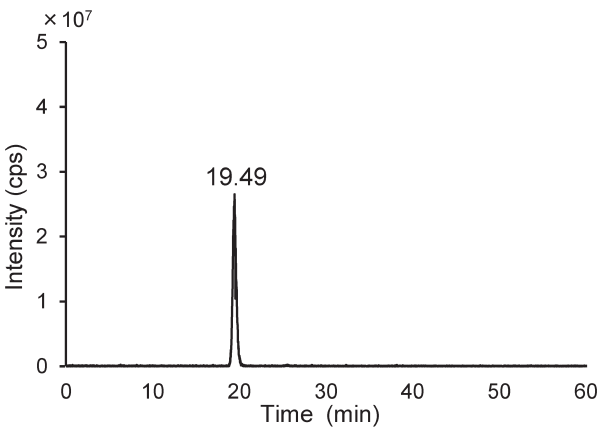

$E$

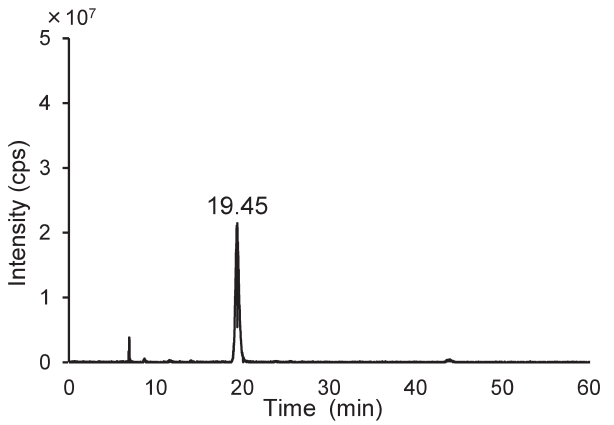

$\mathbf{F}$

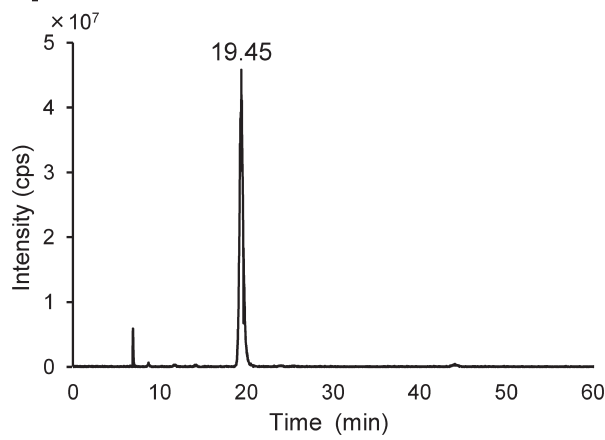

Fig. 3. Extracted ion chromatograms of $m / z 469$ (A); authentic preparation of $3 \beta$-sulfooxy-7 $\beta$-hydroxy-5-cholen-24-oic acid (B); NPC patient urine (C); authentic preparation spiked NPC patient urine and $m / z 467$ (D); authentic preparation of 3 $\beta$-sulfooxy-7-oxo-5-cholen-24-oic acid (E); NPC patient urine (F); authentic preparation spiked NPC patient urine, respectively.

Chromatographic conditions are shown in Experimental section.

serted in Figs. 4A and 4B. The sulfur-containing compound is marked by the appearance of twin peaks at the second isotope position. The accurate mass of the isotope containing one ${ }^{34} \mathrm{~S}$ is $\mathrm{m} / z 471.2218$, present at a relative intensity of approximately $4.5 \%$. The accurate masses of isotopes containing one ${ }^{18} \mathrm{O}$ or two ${ }^{13} \mathrm{C}$ are $\mathrm{m} / z 471.2303$ (1.44\%) and 471.2327 (3.23\%), respectively, and because orbitrap instrument with high mass resolution (a value of $m / \Delta m=140,000$ ) and high mass accuracy $(<5 \mathrm{ppm})$ can separate ${ }^{34} \mathrm{~S}$ from ${ }^{18} \mathrm{O}$ or ${ }^{13} \mathrm{C}_{2}$ but cannot separate the peaks derived from ${ }^{18} \mathrm{O}$ and ${ }^{13} \mathrm{C}_{2}$. Therefore, the 'twin peaks' shown in Fig. 4 were ${ }^{34} \mathrm{~S}$ and sum of $\left({ }^{18} \mathrm{O}\right.$ - and $\left.{ }^{13} \mathrm{C}_{2}\right)$-derived peaks. In the LC-MS/MS analysis, we observed twin peaks in the mass spectra of both the peaks from NPC patient urine and the authentic standard, although their relative intensities differed (insertion in Fig. 4). In a similar manner, we also observed characteristic twin peaks at the second isotope position of $\mathrm{m} / \mathrm{z} 467$ in both mass spectra. A list of the product ions is provided in Table
2C. Both the target compounds found in the NPC patient urine and the authentic standards produced the same product ion corresponding to $\mathrm{HSO}_{4}^{-}$at $m / z$ 96.9607.

We identified two diagnostic marker candidates for NPC, $3 \beta$-sulfooxy-7 $\beta$-hydroxy-5-cholen-24-oic acid and $3 \beta$-sulfooxy-7-oxo-5-cholen-24-oic acid, in the urine of an NPC patient. ${ }^{3)}$ Bile acids commonly have an amino acid group at the $\mathrm{C}-24$ position, and glycine and taurine conjugates of these compounds were present in NPC patient urine (Supplementary data in ref. 3) although their abundances were 3-10-fold lower than those of the non-amidates. ${ }^{3)}$ In humans, glycine and taurine conjugations of bile acids are influenced by diet ${ }^{14-16)}$ accordingly the presence or absence of amino acid conjugation at the C-24 position should not be exploited in NPC diagnostics. $3 \beta$-Sulfooxy-7 $\beta$-hydroxy-5cholen-24-oic acid is the precursor of SNAG- $\Delta^{5}$-CA. UDP glycosyltransferase (UGT) 3A1 catalyzes the transfer of $\mathrm{N}$ acetylglucosamine from UDP $\mathrm{N}$-acetylglucosamine to the 
Table 2. Comparisons between the authentic preparations and two target compounds in the urine of the NPC patient.

(A) Retention time

\begin{tabular}{ccc}
\hline Compound & Sample & Retention time (min) \\
\hline $3 \beta$-Sulfooxy-7 $\beta$-hydroxy-5-cholen-24-oic acid & Authentic & 17.43 \\
& Urine & 17.37 \\
$3 \beta$-Sulfooxy-7-oxo-5-cholen-24-oic acid & Authentic & 19.49 \\
& Urine & 19.45
\end{tabular}

(B) ESI-mass spectra

\begin{tabular}{|c|c|c|c|c|c|}
\hline Compound & $\begin{array}{c}\text { Theoretical mass of } \\
\text { deprotonated } \\
\text { molecules }(\mathrm{m} / \mathrm{z})\end{array}$ & Sample & $\begin{array}{l}\text { Observed mass of de- } \\
\text { protonated molecules } \\
\qquad(\mathrm{m} / z)\end{array}$ & $\begin{array}{l}\text { Difference from } \\
\text { theoretical mass } \\
\qquad(\Delta \mathrm{mmu})\end{array}$ & $\begin{array}{l}\text { Difference from } \\
\text { theoretical mass } \\
\text { (ppm) }\end{array}$ \\
\hline $3 \beta$-Sulfooxy-7 $\beta$-hydroxy- & 469.2260 & Authentic & 469.2268 & -0.81 & 1.726 \\
\hline 5-cholen-24-oic acid & & Urine & 469.2268 & 0.78 & 1.662 \\
\hline $3 \beta$-Sulfooxy-7-oxo-5- & 467.2104 & Authentic & 467.2113 & 0.85 & 1.820 \\
\hline cholen-24-oic acid & & Urine & 467.2111 & 0.70 & 1.498 \\
\hline \multicolumn{6}{|l|}{ (C) Product ion spectra } \\
\hline Precursor ion $(m / z)$ & $\begin{array}{l}\text { Theoretical mass of } \\
\mathrm{HSO}_{4}^{-}(\mathrm{m} / z)\end{array}$ & Sample & $\begin{array}{l}\text { Observed mass of } \\
\text { product ion }(\mathrm{m} / \mathrm{z})\end{array}$ & $\begin{array}{l}\text { Difference from } \\
\text { theoretical mass } \\
\qquad(\Delta \mathrm{mmu})\end{array}$ & $\begin{array}{l}\text { Difference from } \\
\text { theoretical mass } \\
\text { (ppm) }\end{array}$ \\
\hline \multirow[t]{2}{*}{469.23} & 96.9601 & Authentic & 96.9607 & 0.57 & 5.879 \\
\hline & & Urine & 96.9607 & 0.56 & 5.776 \\
\hline \multirow[t]{2}{*}{467.21} & 96.9601 & Authentic & 96.9607 & 0.59 & 6.085 \\
\hline & & Urine & 96.9607 & 0.56 & 5.776 \\
\hline
\end{tabular}

$7 \beta$-hydroxy group on ursodeoxycholic acid, ${ }^{17-19)}$ and Mazzacuva et al. ${ }^{20)}$ reported that the same enzyme catalyzes the transfer of $N$-acetylglucosamine onto $3 \beta, 7 \beta$-dihydroxy-5cholenoic acid. Moreover, the same authors showed that the inactivation of UGT3A1 by genetic mutation suppress the production of $3 \beta$-hydroxy-7 $\beta$-N-acetylglucosaminyl-5cholenoic acid in NPC patients. These observations suggest that the presence or absence of amino acid conjugations and/or $N$-acetylglucosamine at the C-7 $\beta$ and C-24 positions, respectively, are not important for NPC diagnosis. On the other hand, the sulfate conjugation at the C-3 position may not interfere with diagnosis because of the broad substrate specificity of SULT2A1. ${ }^{21)}$ Sulfate conjugation of marker candidates make their excretion into the urine easily, resulting in invasive reduction on the clinical laboratory tests for NPC diagnosis.

\section{CONCLUSION}

We identified two urinary sulfated cholesterol metabolites, $3 \beta$-sulfooxy-7 $\beta$-hydroxy-5-cholen-24-oic acid and $3 \beta$-sulfooxy-7-oxo-5-cholen-24-oic acid, in the urine of an NPC patient, and we consider that compounds represent novel candidate urinary biomarkers for diagnosis of NPC. Measurement of the accurate masses of deprotonated molecules using a Q Exactive orbitrap-quadrupole hybrid mass spectrometer enabled separation of twin peaks unique to the sulfur-containing compounds at the second isotope position of deprotonated molecules. Because these compounds do not undergo $N$-acetylglucosamine conjugation at the C-7 $\beta$ position, they should be useful candidate diagnostic markers for NPC, and should yield a lower level of false-negative results than other markers.

\section{Acknowledgements}

The authors greatly appreciate the kind supply of NPC patient urine from Dr. Aya Narita and Dr. Kousaku Ohno (Present affiliation, Sanin Rosai Hospital) at Faculty of Medicine, Tottori University.

\section{REFERENCES}

1) M. T. Vanier. Niemann-Pick disease type C. Orphanet J. Rare Dis. 5: 16-33, 2010.

2) M. C. Patterson, C. J. Hendriksz, M. Walterfang, F. Sedel, M. T. Vanier, F. Wijburg, NP-C Guidelines Working Group. Recommendations for the diagnosis and management of Niemann-Pick disease type C: An update. Mol. Genet. Metab. 106: 330-344, 2012 .

3) M. Maekawa, M. Shimada, K. Ohno, M. Togawa, H. Nittono, T. Iida, A. F. Hofmann, J. Goto, H. Yamaguchi, N. Mano. Focused metabolomics using liquid chromatography/electrospray ionization tandem mass spectrometry for analysis of urinary conjugated cholesterol metabolites from patients with Niemann-Pick disease type $\mathrm{C}$ and $3 \beta$-hydroxysteroid dehydrogenase deficiency. Ann. Clin. Biochem. 52: 576-587, 2015.

4) G. Alvelius, O. Hjalmarson, W. J. Griffiths, I. Björkhem, J. Sjövall. Identification of unusual 7-oxygenated bile acid sulfates in a patient with Niemann-Pick disease, type C. J. Lipid Res. 42: 1571-1577, 2001.

5) T. Iida, G. Kakiyama, Y. Hibiya, S. Miyata, T. Inoue, K. Ohno, T. Goto, N. Mano, J. Goto, T. Nambara, A. F. Hofmann. Chemical synthesis of the 3-sulfooxy-7-N-acetylglucosaminyl-24-amidated conjugates of $3 \beta, 7 \beta$-dihydroxy-5-cholen-24-oic acid, and related compounds: Unusual, major metabolites of bile acid in a patient with Niemann-Pick disease type C1. Steroids 71: 18-29, 2006.

6) T. Iida, T. Momose, T. Tamura, T. Matsumoto, F. C. Chang, J. Goto, T. Nambara. Potential bile acid metabolites. 14. Hyocholic and muricholic acid stereoisomers. J. Lipid Res. 30: 1267-1279, 1989. 
A

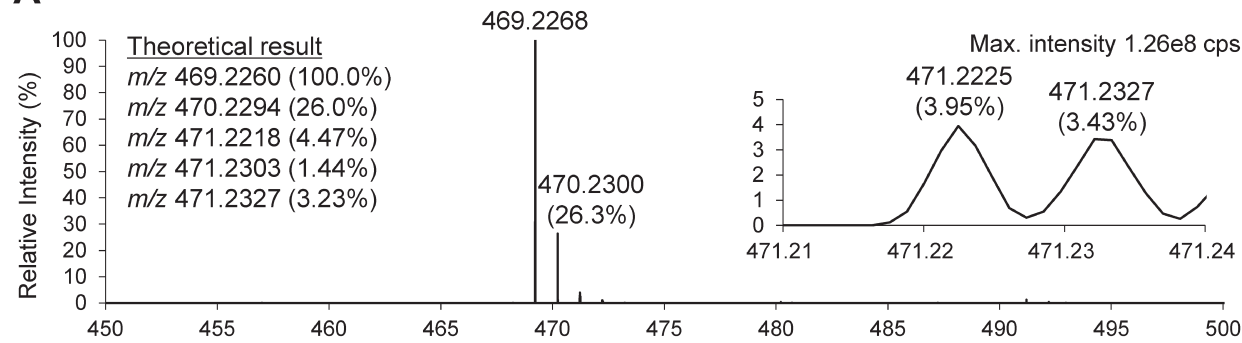

B

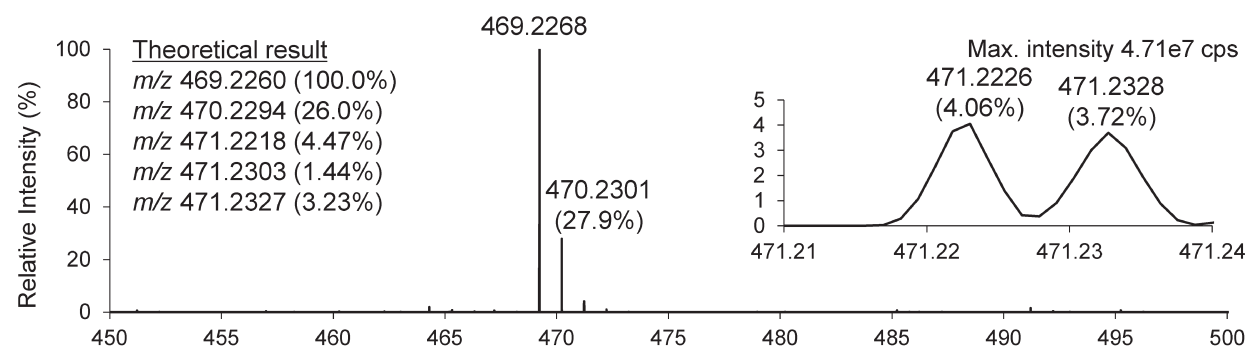

C

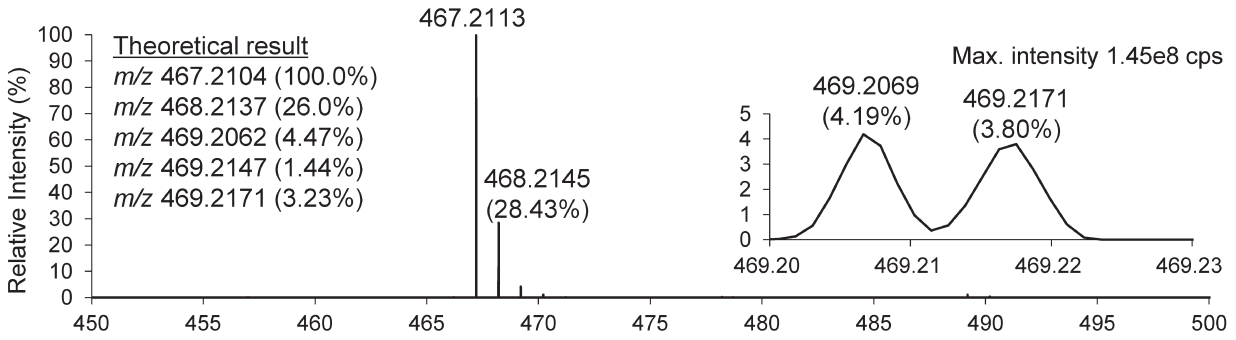

D

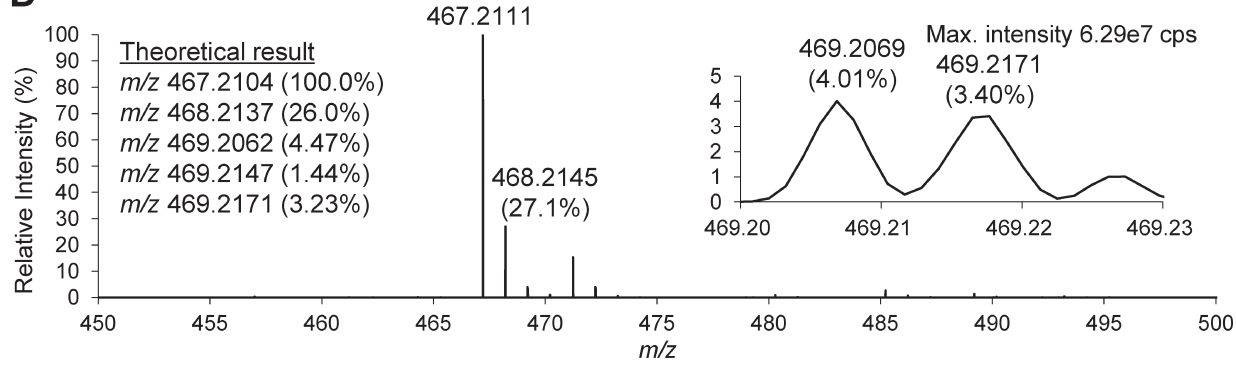

Fig. 4. ESI-MS spectra of NPC patient urine at $17.99 \mathrm{~min}(\mathrm{~A})$; the authentic preparation of $3 \beta$-sulfooxy-7 $\beta$-hydroxy-5-cholen-24-oic acid (B); NPC patient urine at $20.12 \mathrm{~min}$ (C); and authentic preparation of $3 \beta$-sulfooxy-7-oxo-5-cholen-24-oic acid (D), respectively.

Theoretical accurate masses of $m / z 469,470$, and 471 produced from $\mathrm{C}_{24} \mathrm{H}_{38} \mathrm{O}_{7} \mathrm{~S}$ are shown in the inserted list in (A, B), and those of $m / z$ 467, 468, and 469 produced from $\mathrm{C}_{24} \mathrm{H}_{36} \mathrm{O}_{7} \mathrm{~S}$ are shown in the inserted list in (C, D). The inserted spectra show twin peaks at each second isotopic position with accurate masses and abundances. Chromatographic and mass spectrometric conditions are shown in Experimental section.

7) P. T. Clayton, J. V. Leonard, A. M. Lawson, K. D. R. Setchell, S. Andersson, B. Egestad, J. Sjövall. Familial giant cell hepatitis associated with synthesis of $3 \beta, 7 \alpha$-dihydroxy- and $3 \beta, 7 \alpha, 12 \alpha$ trihydroxy-5-cholenoic acids. J. Clin. Invest. 79: 1031-1038, 1987.

8) H. Ichimiya, B. Egestad, H. Nazer, E. S. Baginski, P. T. Clayton, J. Sjövall. Bile acids and bile alcohols in a child with hepatic $3 \beta$-hydroxy- $\Delta^{5}-\mathrm{C}_{27}$-steroid dehydrogenase deficiency: Effects of chenodeoxycholic acid treatment. J. Lipid Res. 32: 829-841, 1991.

9) T. Nambara, J. Goto. in The Bile Acids, Vol. 4. (Eds: K. D. R. Setchell, D. Kritchevsky, P. P. Nair), Chapter 2, High-performance liquid chromatography, Plenum Publishing, New York, 1988, pp. 43-64.

10) J. Sjövall, W. J. Griffiths, K. D. R. Setchell, N. Mano, J. Goto. in Steroid Analysis, 2nd Ed. (Eds: H. L. J. Makin, D. B. Gower), Chapter 10, Analysis of bile acids, Springer, Dordrecht, Heidel- berg, London, New York, 2010, pp. 837-966.

11) N. Mano, Y. Sato, M. Nagata, T. Goto, J. Goto. Bioconversion of $3 \beta$-hydroxy-5-cholenoic acid into chenodeoxycholic acid by rat brain enzyme systems. J. Lipid Res. 45: 1741-1748, 2004.

12) M. Maekawa, Y. Misawa, A. Sotoura, H. Yamaguchi, M. Togawa, K. Ohno, H. Nittono, G. Kakiyama, T. Iida, A. F. Hofmann, J. Goto, M. Shimada, N. Mano. LC/ESI-MS/MS analysis of urinary $3 \beta$-sulfooxy-7 $\beta$ - $N$-acetylglucosaminyl-5-cholen-24-oic acid and its amides: New biomarkers for the detection of Niemann-Pick type C disease. Steroids 78: 967-972, 2013.

13) L. W. Summer, A. Amberg, D. Barrett, M. H. Beale, C. A. Daykin, T. W. M. Fan, O. Fiehn, R. Goodacre, J. L. Griffin, T. Hankemeier, N. Hardy, J. Harnly, R. Higashi, J. Kopka, A. N. Lane, J. C. Lindon, P. Marriott, A. W. Nicholls, M. D. Reily, J. J. Thaden, M. R. Viant. Proposed minimum reporting standards for chemical 
analysis Chemical Analysis Working Group (CAWG) Metabolomics Standards Initiative (MSI). Metabolomics 3: 211-221, 2007.

14) S. P. R. Bathena, R. Thakare, N. Gautam, S. Mukherjee, M. Olivera, J. Meza, Y. Alnouti. Urinary bile acids as biomarkers for liber diseases I. Stability of the baseline profile in healthy subjects. Toxicol. Sci. 143: 296-307, 2015.

15) I. Bobeldijk, M. Hekman, J. V. Weij, L. Coulier, R. Ramaker, R. Kleemann, T. Kooistra, C. Rubingh, A. Freidig, E. Verheij. Quantitative profiling of bile acids in biofluids and tissues based on accurate mass high resolution LC-FT-MS: Compound class targeting in a metabolomics workflow. J. Chromatogr. B Analyt. Technol. Biomed. Life Sci. 871: 306-313, 2008.

16) A. Tangerman, A. Schaik, E. W. Hoek. Analysis of conjugated and unconjugated bile acids in serum and jejunal fluid of normal subjects. Clin. Chim. Acta 159: 123-132, 1986.

17) H. Matern, R. Bolz, H. U. Marschall, J. Sjövall, S. Matern. Bile acid $\mathrm{N}$-acetylglucosaminides. Formation by microsomal $\mathrm{N}$ acetylglucosaminyltransferases in human liver and kidney. FEBS
Lett. 270: 11-14, 1990.

18) H. U. Marschall, H. Matern, H. Wietholz, B. Egestad, S. Matern, J. Sjövall. Bile acid $\mathrm{N}$-acetylglucosaminidation. In vivo and in vitro evidence for a selective conjugation reaction of $7 \beta$-hydroxylated bile acids in humans. J. Clin. Invest. 89: 19811987, 1992.

19) P. I. Mackenzie, A. Rogers, J. Treloar, B. R. Jorgenson, J. O. Miners, R. Meech. Identification of UDP glycosyltransferase 3A1 as a UDP $N$-acetylglucosaminyltransferase. J. Biol. Chem. 283: 36205-36210, 2008.

20) F. Mazzacuva, P. Mills, K. Mills, S. Camuzeaux, P. Gissen, E. R. Nicoli, C. Wassif, D. Vruchte, F. D. Porter, M. Maekawa, N. Mano, T. Iida, F. Platt, P. T. Clayton. Identification of novel bile acids as biomarkers for the early diagnosis of Niemann-Pick C disease. FEBS Lett. 590: 1651-1662, 2016.

21) Y. Alnouti. Bile acid sulfation: A pathway of bile acid elimination and detoxification. Toxicol. Sci. 108: 225-246, 2009. 